\title{
Effect of Aerobic Exercise Training on Body Mass Index and Functional Performance in Diabesity Women under Intermittent Fasting 16/8 Protocol
}

\author{
EMAN R.A. EL-SAYED, M.Sc.*; NESREEN G. EL-NAHAS, Ph.D.**; SALLY A. HAKIM, M.D.*** and \\ AZZA A. ABD EL-HADY, Ph.D.**
}

The Department of Physical Therapy for Cardiovascular Respiratory Disorders \& Geriatrics, Faculty of Physical Therapy, Horus* and Cairo** Universities and The Department of Community, Environmental \& Occupational Medicine, Faculty of Medicine, Ain Shams University***

\begin{abstract}
Background: The increased number of patients suffer from diabesity provoke the scientific researchers to deal with its complications either acute or chronic as well as increasing the debate about the effect of aerobic exercises with intermittent fasting 16/8 protocol in modulating this issue.

Aim of Study: The current study aimed to determine the effect of aerobic exercise on metabolic profile in diabesity patients under intermittent fasting $16 / 8$ protocol.

Material and Methods: Forty women diabesity patients with mean age $40.2 \pm 2.98$ years old. They are diabetic since 5-7 years with class II obesity according to their Body Mass Index (BMI) classification and were assigned randomly using the sealed envelope method of randomization into two groups equal in number. Both groups were under controlled diet regimen with the protocol of intermittent fasting 16/8. Group A performed treadmill aerobic exercise for 3 times/week during the fasting period (window) with intensity of 40-60\% of the Maximum Heart Rate (MHR) for 12 weeks \& Group B performed treadmill aerobic exercise for 3 times/week during the eating period (window). According to training intensity with $40-60 \%$ of maximum heart rate for 12 weeks participated in the study BMI, Glycosylated hemoglobin $\left(\mathrm{HbA}_{l_{\mathrm{c}}}\right)$ and 6 minute walk test were used for assessment at baseline and after 12 weeks of training.

Results: The results revealed that there was significant reduction of BMI in Group A (9.19\%) and Group B (7.12\%), and in HbA $_{1 \mathrm{c}}$ Group A (20.7\%) and Group B (13.91\%) and significant increase of 6 MWT in Group A (23.8\%) and Group B $(18.36 \%)$ in compare to pre-treatment in both groups. Unpaired $t$-test revealed that there was significant difference of the mean values of the "post" test between both groups in $\mathrm{HbA}_{1 \mathrm{c}}$ and $6 \mathrm{MWT}$. This significant difference in favor to Group A than Group B. There was no statistical difference between both groups of the mean values of the "post" test in BMI.
\end{abstract}

Correspondence to: Dr. Eman R.A. El-Sayed, The Department of Physical Therapy for Cardiovascular Respiratory Disorders \& Geriatrics, Faculty of Physical Therapy, Horus University
Conclusion: Intermittent fasting 16/8 protocol with controlled diet regimen and treadmill aerobic exercise for 3 times/ week during the fasting period is the best way to decrease body weight, controlling blood glucose and enhance functional performance in diabesity women.

Key Words: Aerobic exercise - Diabesity - Intermittent fasting - Functional performance

\section{Introduction}

Diabetes Mellitus (DM) is a group of metabolic disorders in which there are high blood glucose levels over a prolonged period of time. Its Symptoms include polyurea, polydypsia, and polyphagia. If left untreated, diabetes can cause many complications. Acute complications may include diabetic ketoacidosis, hyperosmolar hyperglycemic state, or death. Serious long-term complications include cardiovascular disease, stroke, chronic kidney disease, foot ulcers, and damage to the eyes [1].

Hyperglycemia is the main characteristic symptom of diabetes, resulting from defects in insulin secretion and or increased cellular resistance to insulin, chronic hyperglycemia and other metabolic disturbances of DM lead to long term tissue and organ damage as well as dysfunction [2] .

Obesity is associated with elevated vascular risk in population studies. In addition, this condition has been associated with glucose intolerance, insulin resistance, hypertension, physical inactivity, and dyslipidemia [3] . About $7 \%$ of the population has diabetes and patients with diabetes are 2-8 times more likely to experience future cardiovascular events than age-matched and ethnically matched individuals without diabetes, and a recent study suggested a potential reduction of all-cause 
and cardiovascular disease-specific mortality in women with controlled diabetes mellitus [4].

There are different types of intermittent fasting as alternate-day fasting, modified fasting regimen and time-restricted feeding. A growing body of evidence suggests that, in general, Intermittent Fasting (IF) 16/8 could represent an useful tool for improving health in general population due to reports of improving blood lipids and glycaemic control, reducing circulating insulin, decreasing blood pressure, decreasing inflammatory markers and reducing fat mass even during relatively short durations. These reported effects are probably mediated through changes in metabolic pathways and cellular processes such as stress resistance, lipolysis, and autophagy. One particular form of IF which has gained great popularity through mainstream media is the so-called Time-Restricted Feeding (TRF) [5]. As to consider as a life coaching training to live healthy and independent in society. This type of exercise will affect diabetes as well as obesity.

Thus there is a need to investigate if there is an effect of aerobic exercise on metabolic profile in diabesity patients under intermittent fasting 16/8 protocol.

\section{Material and Methods}

This study was conducted in outpatient clinic of Internal Medicine in El-Mansoura General Hospital, Egypt from July to November 2018. Forty women diabesity patients with age ranged from $35-45$ years old. They had diabetes of type 2 since 5-7 years with $\mathrm{HbA}_{1 \mathrm{c}}$ is $6.5 \%-8 \%$ and classified as class II obesity according to their body mass index classification $\left(\mathrm{BMI}=35-39.9 \mathrm{Kg} / \mathrm{m}^{2}\right)$. All patients signed a consent form prior to participation. The approval from the Faculty of Physical Therapy Ethical Committee. (NO.P.T.REC/012/002028/ $15 / 7 / 2018$ ) patients were excluded if they had any of the following; (uncontrolled diabetes mellitus, smokers, orthopedic problems, e.g. disk or knee problems, cardiac disease and gynecological problems as uterine prolapsed and retroversion flexion). Patients were assigned randomly using the sealed envelope method of randomization into two equal groups in number (A \& B); Group (A) received intermittent fasting $16 / 8$ protocol with controlled diet regimen [6] and received treadmill aerobic exercise during the fasting (window) with intensity of $40-60 \%$ of Maximum Heart Rate (MHR) and Group (B) received intermittent fasting $16 / 8$ protocol with controlled diet regimen and received treadmill aerobic exercise during the eating period with intensity 40-60\% of MHR. The training period of the study was 3 times/week for 12 weeks.

Procedures: For evaluation weight and height scale was used to measure body mass index with the relation of body weight $(\mathrm{kg}) /$ height $\left(\mathrm{m}^{2}\right)$ and $\mathrm{HbA}_{1 \mathrm{c}}$ Uniten device as to measure the level of glycosylated hemoglobin. Six minute walk test was applied as to assess the functional capacity of the patients these evaluation procedures were done at baseline and reassessed after 12 weeks of training.

For training electronic treadmill (Motorized treadmill model no: $1108 \mathrm{~b} 4$ g.w/n.w:55/50) to exercise training.

\section{Results}

The current study was conducted on 40 participants. They were assigned into two equal groups in number. Group (A) consisted of 20 participants with mean age, height, weight and BMI values of $40.6 \pm 2.77$ years, $1.62 \pm 0.047 \mathrm{~m}$, and $97.92 \pm 5.84 \mathrm{~kg}$ and $37.2 \pm 1.74 \mathrm{~kg} / \mathrm{m}^{2}$ respectively. Group (B) consisted of 20 participants with mean age and height values of $39.8 \pm 3.23$ years, $1.61 \pm 0.042 \mathrm{~m}, 96.66 \pm$ $5.25 \mathrm{~kg}$ and $37.17 \pm 1.98 \mathrm{~kg} / \mathrm{m}^{2}$ respectively. As indicated by the independent $t$-test, there were no significant differences $(p>0.05)$ in the mean values of age, weight, BMI and height between both tested groups (Table 1).

Table (1): Physical characteristics of participants in both Groups (A \& B).

\begin{tabular}{|c|c|c|c|c|c|}
\hline \multirow{2}{*}{ Items } & \multirow{2}{*}{$\begin{array}{c}\text { Group A } \\
\text { Mean } \pm \text { SD }\end{array}$} & \multirow{2}{*}{$\begin{array}{c}\text { Group B } \\
\text { Mean } \pm \text { SD }\end{array}$} & \multicolumn{2}{|c|}{ Comparison } & \multirow{2}{*}{$S$} \\
\hline & & & $t$-value & $p$-value & \\
\hline Age (years) & $40.6 \pm 2.77$ & $39.8 \pm 3.23$ & 0.838 & 0.407 & NS \\
\hline Weight (kg) & $97.92 \pm 5.84$ & $96.66 \pm 5.25$ & 0.717 & 0.478 & NS \\
\hline Height (m) & $1.62 \pm 0.047$ & $1.61 \pm 0.042$ & 0.672 & 0.506 & NS \\
\hline BMI $\left(\mathrm{kg} / \mathrm{m}^{2}\right)$ & $37.2 \pm 1.74$ & $37.17 \pm 1.98$ & 0.043 & 0.966 & NS \\
\hline
\end{tabular}

As presented in (Table 2) within group's comparison the mean \pm SD values of BMI in the "pre" and "post" tests were $37.2 \pm 1.74$ and $33.78 \pm 1.49$ respectively in the Group (A). Paired $t$-test revealed that there was significant reduction of BMI at post training in compare to pre training where their $t$ and $p$-values were $(t$-value $=25.258, p$-value $=$ $0.0001 *)$. As well, the mean \pm SD values of BMI in the "pre" and "post" tests were $37.17 \pm 1.98$ and $34.52 \pm 1.66$ respectively in the Group (B). Paired $t$-test revealed that there was significant reduction of BMI at post training in compare to pre training where their $t$ and $p$-values were $(t$-value $=25.393$, 
$p$-value $=0.0001 *)$. Within group's comparison the mean \pm SD values of HbA $_{1 \mathrm{c}}$ in the "pre" and "post" tests were $7.34 \pm 0.46$ and $5.82 \pm 0.72$ respectively in the Group (A). Paired $t$-test revealed that there was significant reduction of $\mathrm{HbA}_{1 \mathrm{c}}$ at post training in compare to pre training where their $t$ and $p$ values were $(t$-value $=8.894, p$-value $=0.0001 *)$. As well, the mean \pm SD values of $\mathrm{HbA}_{1 \mathrm{c}}$ in the "pre" and "post" tests were $7.26 \pm 0.45$ and $6.25 \pm 0.45$ respectively in the Group (B). Paired $t$-test revealed that there was significant reduction of $\mathrm{HbA}_{1 \mathrm{c}}$ at training treatment in compare to pre training where their $t$ and $p$-values were ( $t$-value $=21.01, p$-value $=0.0001 *)$. Within group's comparison the mean \pm SD values of 6 MWT in the "pre" and "post" tests were $409.7 \pm 6.02$ and $507.3 \pm 5.86$ respectively in the Group (A). Paired $t$-test revealed that there was significant increase of 6 MWT at post training in compare to pre training where their $t$ and $p$ values were $(t$-value $=52.67, p$-value $=0.0001 *)$. As well, the mean \pm SD values of 6 MWT in the "pre" and "post" tests were $407.5 \pm 4.60$ and $482.3 \pm 6.26$ respectively in the Group (B). Paired $t$-test revealed that there was significant increase of 6 MWT at post training in compare to pre training where their $t$ and $p$-values were $(t$-value $=-51.83$, $p$-value $=0.0001 *$ ).

Table (2): Statistical analysis for measured parameters throughout the study.

\begin{tabular}{|c|c|c|c|c|c|c|}
\hline & $\begin{array}{c}\text { Pre test } \\
\text { Mean } \pm \text { SD }\end{array}$ & $\begin{array}{c}\text { Post test } \\
\text { Mean } \pm \text { SD }\end{array}$ & MD & $\begin{array}{c}\% \text { of } \\
\text { change }\end{array}$ & $\begin{array}{c}t- \\
\text { value }\end{array}$ & $\begin{array}{c}p- \\
\text { value }\end{array}$ \\
\hline $\begin{array}{l}B M I: \\
\text { - Group A } \\
\text { - Group B } \\
\text { - MD } \\
\text { - } t \text {-value } \\
\cdot p \text {-value }\end{array}$ & $\begin{array}{l}37.2 \pm 1.74 \\
37.17 \pm 1.98 \\
0.03 \\
0.043 \\
0.966\end{array}$ & $\begin{array}{l}33.78 \pm 1.49 \\
34.52 \pm 1.66 \\
-0.74 \\
-1.482 \\
0.147\end{array}$ & $\begin{array}{l}3.42 \\
2.65\end{array}$ & $\begin{array}{l}\downarrow 9.19 \% \\
\downarrow 7.12 \%\end{array}$ & $\begin{array}{l}25.258 \\
25.393\end{array}$ & $\begin{array}{l}0.0001 * \\
0.0001 *\end{array}$ \\
\hline $\begin{array}{l}H b A 1_{c}: \\
\text { - Group A } \\
\text { - Group B } \\
\text { - MD } \\
\text { - } t \text {-value } \\
\text { - } p \text {-value }\end{array}$ & $\begin{array}{l}7.34 \pm 0.46 \\
7.26 \pm 0.45 \\
0.08 \\
0.551 \\
0.585\end{array}$ & $\begin{array}{l}5.82 \pm 0.72 \\
6.25 \pm 0.45 \\
-0.43 \\
-2.293 \\
0.027^{*}\end{array}$ & $\begin{array}{l}1.52 \\
1.01\end{array}$ & $\begin{array}{l}\downarrow 20.7 \% \\
\downarrow 13.91 \%\end{array}$ & $\begin{array}{l}8.894 \\
21.01\end{array}$ & $\begin{array}{l}0.0001 * \\
0.0001 *\end{array}$ \\
\hline $\begin{array}{l}6 M W T: \\
\text { - Group A } \\
\text { - Group B } \\
\text { - MD } \\
\text { - } t \text {-value } \\
\cdot p \text {-value }\end{array}$ & $\begin{array}{l}409.7 \pm 6.02 \\
407.5 \pm 4.60 \\
2.2 \\
1.299 \\
0.101\end{array}$ & $\begin{array}{l}507.3 \pm 5.86 \\
482.3 \pm 6.26 \\
25 \\
13.04 \\
0.0001 *\end{array}$ & $\begin{array}{l}-97.6 \\
-74.8\end{array}$ & $\begin{array}{l}\uparrow 23.8 \% \\
\uparrow 18.36 \%\end{array}$ & $\begin{array}{l}-52.67 \\
-51.83\end{array}$ & $\begin{array}{l}0.0001 * \\
0.0001 *\end{array}$ \\
\hline $\begin{array}{ll} & : \\
\text { SD } & :\end{array}$ & $\begin{array}{l}\text { Significant le } \\
\text { Standard Dev } \\
\text { Mean Differe }\end{array}$ & $\begin{array}{l}\text { vel is set at al } \\
\text { iation. } \\
\text { nce. } \\
\text { alue. }\end{array}$ & & $1<0.05$. & & \\
\hline
\end{tabular}

Considering the effect of the tested group (first independent variable) on BMI, unpaired $t$-test revealed that the mean values of the "pre" test between both groups showed no significant differences with their $t$ and $p$-values were $(t$-value $=$
$0.043, p=0.966)$. As well as, unpaired $t$-test revealed that there was no significant difference of the mean values of the "post" test between both groups with their $t$ and $p$-values were $(t$-value $=-1.482, p=0.147)$. However, there was no statistical difference between both groups; there was clinical difference and higher percent of improvement in favor to Group A (9.19\%) than Group B (7.12\%). Considering the effect of the tested group (first independent variable) on $\mathrm{HbA}_{1_{\mathrm{c}}}$, unpaired $t$-test revealed that the mean values of the "pre" test between both groups showed no significant differences with their $t$ and $p$-values were $(t$-value $=0.551, p=0.585)$. As well as, unpaired $t$-test revealed that there was significant difference of the mean values of the "post" test between both groups with their $t$ and $p$-values were $(t$-value $=-2.293, p=0.027 *)$. This significant reduction in favor to Group A (20.7\%) than Group B (13.91\%). Considering the effect of the tested group (first independent variable) on 6 MWT, unpaired $t$-test revealed that the mean values of the "pre" test between both groups showed no significant differences with their $t$ and $p$-values were $(t$-value $=1.299, p=0.101)$. As well as, unpaired $t$ test revealed that there was significant difference of the mean values of the "post" test between both groups with their $t$ and $p$-values were $(t$-value $=$ $\left.13.04, p=0.0001^{*}\right)$. This significant increase in favor to Group A (23.8\%) than Group B (18.36\%).

\section{Discussion}

In the current study we have used a very simple intervention protocol with the aim of mimicking the perturbations in energy stores that are mixing intermittent fasting with regular exercise training. In a wider perspective we have tried to unravel the significance of genes that may be responsible for an evolutionary selection process, i.e., the thrifty genes. In this context the used intervention seems inevitably small. Nevertheless, by subjecting healthy men to cycles of feast and famine we did change the metabolic status to the better, implying that the mismatch between our ancient genotype and the lifestyle of the westernized individual of today became smaller. To our knowledge this is the first study in humans in which an increased insulin action on whole body glucose uptake and adipose tissue lipolysis has been obtained by means of intermittent fasting and exercise training comparing the training period in fasting or eating window.

The results revealed that there was significant reduction of BMI in Group A (9.19\%) and Group B (7.12\%), and in ${ }_{\mathrm{HbA}_{1 c}}$ Group A (20.7\%) and 
Group B (13.91\%) and significant increase of 6 MWT in Group A $(23.8 \%)$ and Group B $(18.36 \%)$ in compare to pre-treatment in both groups. Findings of current study are in line with three intervention studies that explored the metabolic effects of alternate-day fasting [7-9]. Sample sizes were modest and ranged from 8 to 30 normal weight adults and 10 overweight or obese adults [7]. No information was provided about the physical activity levels of these participants. Two of three studies reported significant weight loss, although we question the clinical relevance of weight loss in a 1day study [9]. In the 22-day study of alternate-day fasting, participants experienced a mean $2.5 \%$ weight loss $(p<0.001)$ [8]. Three of the studies found a significant decrease in at least one glucoregulatory marker.

One caveat of this research is that three of these four studies enrolled normal weight adults who were unlikely to show substantial improvements in metabolic risk factors. Although not a focus of this review, hunger and mental status, as well as post-fast energy intake, are important outcomes to consider with extended fasting during waking hours. Appleton \& Baker [10] recently reported that in women $(n=16)$, a 2 -day fast resulted in distraction, but not hunger, and was associated with lower mood and perceived work performance compared with 2 days prior to and following the fasting period.

Antoni et al., [7] observed that a 1-day fast resulted in a 30\% reduction in energy intake 3 days post-fast. Heilbronn et al., [8] noted that participants reported considerable hunger on fasting days, which did not decrease over time. The sparse data on alternate-day fasting suggest that this regimen can result in modest weight loss and lead to improvements in some metabolic parameters. However, reports of extreme hunger while fasting indicate that this may not be a feasible public health intervention.

There is no doubt, however, that fasting for 20 hours(h) while maintaining normal daily physical activity must cause a temporary negative energy balance larger than normally experienced in a daily basis. This is also indicated by our finding of decreased plasma glucose concentrations after 20$\mathrm{h}$ fasting. We did not have the possibility to estimate the hepatic glycogen stores, but from animal studies [11] we must infer that liver glycogen probably also decreased considerably during the 20 -h fasting periods. It has previously been suggested that usage of muscle energy depots during fasting would be an evolutionary disadvantage, because it would lessen the capacity for physical performance and hence the ability to provide food (i.e., to hunt and gather) during periods of fasting [12]. The current findings support this view. In contrast to the findings in skeletal muscle, the adipose tissue responded to the changes in energy balance as intermittent fasting changed the plasma concentrations of the adipocyte-specific hormones leptin and adiponectin [13].

Obesity, especially the marked type, is predictive of 6 MWD decline $[\mathbf{1 4 , 1 5}]$. This confirms once more the adverse effects of obesity on aerobic capacity [14], and suggests that the obesity-NIDDM association accelerates $6 \mathrm{MWD}$ decline. This result is an important argument to encourage NIDDM patients to start a diet and/or regular exercise [16].

This is consistent with Kelly et al., [17] who investigated the impact of nitrate supplementation on exercise performance using the 6 MWT (in healthy older 24 individuals). Since any improvement in walking performance could reasonably be assumed to be underpinned by alterations in the $\mathrm{VO} 2$ response to exercise, and considering that this was not modulated by nitrate supplementation, it is perhaps not surprising that functional capacity was also not different between conditions. It is likely that the explanation for the lack of effect of nitrate supplementation on walking performance is synonymous with the potential explanations for the lack of effect on the $\mathrm{O}_{2}$ cost of exercise.

Regarding to within groups comparison in 6 MWT there was significant increase of the mean values of the "post" test between both groups. This significant increase in favor to Group A $(23.8 \%)$ than Group B (18.36\%). Results of this study are coincided with results achieved by Sperandio et al., [18] who stated that the 6 MWT represents a moderate-to-high intensity activity in middle-aged and older adults and proved to be useful for predicting cardio-respiratory fitness in the present study. The results suggested that the 6 MWT may also be useful in asymptomatic individuals, and its use in walk-based conditioning programs should be encouraged.

Findings of current study are in line with that of Fiorina et al., [19] who stated that the 6 MWT is feasible and well tolerated in adult and older patients shortly after uncomplicated cardiac surgery. The results indicate that the functional capacity, as expressed by distance walked during the 6 MWT, is significantly reduced shortly after cardiac surgery 
and quickly improves after physical training. The improvement is observed independently of age, sex, co-morbid conditions and baseline functional capacity.

Even a single fasting interval in humans (e.g., overnight) can reduce basal concentrations of many metabolic biomarkers associated with chronic disease, such as insulin and glucose. For example, patients are required to fast for 8-12 hours before blood draws to achieve steady-state fasting levels for many metabolic substrates and hormones [20]

An important clinical and scientific question is whether adopting a regular, intermittent fasting regimen is a feasible and sustainable populationbased strategy for promoting metabolic health. Further, properly powered, controlled clinical research is needed to test whether intermittent fasting regimens can complement or replace energy restriction and, if so, whether they can facilitate long-term metabolic improvements and body weight management. The summary points are supported by the current evidence [20]

Additionally, intermittent fasting regimens attempt to translate the positive effects of fasting regimens in rodents and other mammals into practical eating patterns for reducing the risk of chronic disease in humans. In the future issues section, we suggest issues that should be addressed in research investigating intermittent fasting and metabolic health [20]

\section{Conclusion:}

Finally it can be concluded that intermittent fasting 16/8 protocol with controlled diet regimen and treadmill aerobic exercise during the fasting or the eating period (window) has good impact in improving metabolic profile, but intermittent fasting $16 / 8$ protocol with controlled diet regimen and treadmill aerobic exercise during the fasting (window) has great impact on decreasing of $\mathrm{HbA} 1_{c}$ and significant increase of 6 MWT distance in favor to applying the training in the fasting window.

\section{References}

1- MALIK V.S., POPKIN B.M., BRAY G.A., DESPRÉS J.P. and HU F.B.: "Sugar-sweetened beverages, obesity, type 2 diabetes mellitus, and cardiovascular disease risk". Circulation, 121 (11): 1356-64, 2017.

2- American Diabetes Association: Diagnosis and classification of diabetes mellitus. Diabetes Care, 31: S55-S60, 2014.

3- BACHA F., EDMUNDOWICZ D., SUTTON-TYRELL K., LEE S., TFAYLI H. and ARSLANIAN S.A.: Coronary artery calcification in obese youth: what are the phenotypic and metabolic determinants? Diabetes Care, 37 (9): 26329, 2014.

4- HE M., VAN DAM R.M., RIMM E., HU F.B. and QI L.: Whole-grain, cereal fiber, bran, and germ intake and the risks of all-cause and cardiovascular disease-specific mortality among women with type 2 diabetes mellitus. Circulation, 121 (20): 2162-8, 2010.

5- BARNOSKY A.R., HODDY K.K., UNTERMAN T.G and VARADY K.A.: Intermittent fasting versus daily calorie restriction for type 2 diabetes prevention: A review of human findings. Transl. Res., 164: 302-11, 2014.

6- IOANNIS ARKADIANOS, ANA M. VALDES, EFSTATHIOS MARINOS, ANNA FLOROU, ROSALYNN D. GILL and KEITH A. GRIMALDI: Improved weight management using genetic information to personalize a calorie controlled diet. Nutr. J., 6: 29, 2014.

7- ANTONI R., JOHNSTON K.L., COLLINS A.L. and ROBERTSON M.D.: Investigation into the acute effects of total and partial energy restriction on postprandial metabolism among overweight/obese participants. Br. J. Nutr., 115: 951-9, 2016.

8- HEILBRONN L.K., SMITH S.R., MARTIN C.K., ANTON S.D. and RAVUSSIN E.: Alternate-day fasting in nonobese subjects: Effects on body weight, body composition, and energy metabolism. Am. J. Clin. Nutr., 81: 6973, 2005.

9- HORNE B.D., MUHLESTEIN J.B., LAPPE D.L., MAY H.T., CARLQUIST J.F., et al.: Randomized cross-over trial of short-term water-only fasting: Metabolic and cardiovascular consequences. Nutr. Metab. Cardiovasc. Dis., 23: 1050-57, 2013.

10-APPLETON K.M. and BAKER S.: Distraction, not hunger, is associated with lower mood and lower perceived work performance on fast compared to non-fast days during intermittent fasting. J. Health Psychol., 20: 702-11, 2015.

11- EXTON J.H., CORBIN J.G. and HARPER S.C.: Control of gluconeogenesis in liver. V. Effects of fasting, diabetes, and glucagon in lactate and endogenous metabolism in the perfused rat liver. J. Biol. Chem., 247: 4996-5003, 1972.

12- STANNARD S.R. and JOHNSON N.A.: Insulin resistance and elevated triglyceride in muscle: More important for survival than "thrifty" genes? J. Physiol., 554: 595-607, 2004.

13- CHAKRAVARTHY M.V. and BOOTH F.W.: Eating, exercise, and "thrifty" genotypes: Connecting the dots toward an evolutionary understanding of modern chronic diseases. J. Appl. Physiol., 96: 3-10, 2004.

14- American Thoracic Society: ATS statement: Guidelines for the six minute walk test. Am. J. Respir. Crit. Care Med., 16: 111-7, 2002.

15- TROOSTERS T., GOSSELINK R. and DECRAMER M.: Six minute walking distance in healthy elderly subjects. Eur. Respir. J., 14: 270-4, 1999.

16- DUNSTAN D.W., PUDDEY I.B., BURKE V., STANTON K.G., MORTON A.R. and BEILIN L.J.: Effects of a shortterm circuit weight training program on glycaemic control in NIDDM. Diabetes Res. Clin. Pract., 40: 53-61, 1998.

17- KELLY J., FULFORD J., VANHATALO A., et al.: Effects of short-term dietary nitrate supplementation on blood 
pressure, $\mathrm{O}_{2}$ uptake kinetics, and muscle and cognitive function in older adults. Am. J. Physiol. Regul. Integr. Comp. Physiol, 304 (2): 21, 2013.

18- SPERANDIO E.F., ARANTES R.L., MATHEUS A.C., SILVA R.P., LAURIA V.T., ROMITI M., GAGLIARDI A.R.T. and DOURADO V.Z.: Intensity and physiological responses to the 6-minute walk test in middle-aged and older adults: A comparison with cardiopulmonary exercise testing. Braz. J. Med. Biol. Res., 00 (00): 1-5, 2015.
19- FIORINA C., VIZZARDI E., LORUSSO R., MAGGIO M., De CICCO G., NODARI S., FAGGIANO P. and DEI CAS L.: The 6-min walking test early after cardiac surgery. Reference values and the effects of rehabilitation program me. European Journal of Cardio-thoracic Surgery, 32: 724-9, 2007.

20- PATTERSON R.E. and SEARS D.D.: Metabolic effects of intermittent fasting. Annu. Rev. Nutr., 37: 371-93, 2007.

\title{
تآثير التمارين الهوائية على مؤشر كتلة الجسه والآداء الوظيفى الهئي

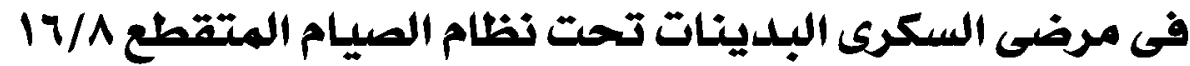

\author{
الفرض: هدفت الدراسة الحالية إلى تحديد تآثير التمرينات الهوائية على المظهر الآيضى فى مرضى السكرى تحت الصيام المتقطع 11Y/.

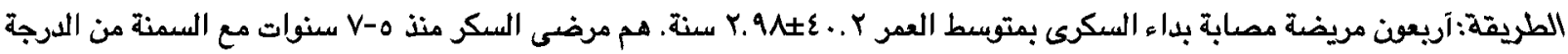

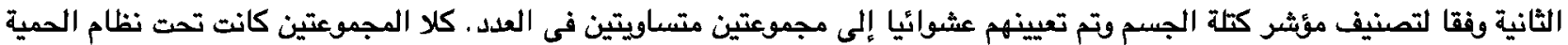

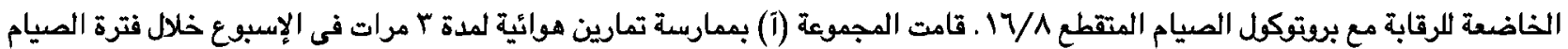

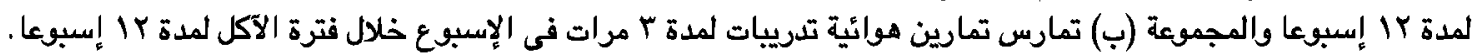

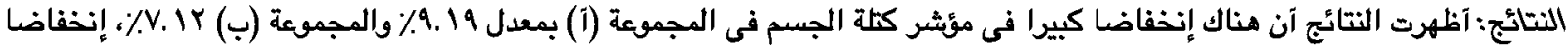

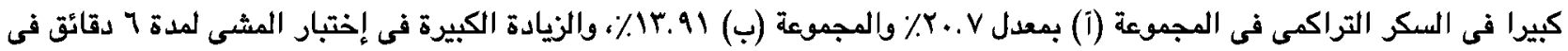

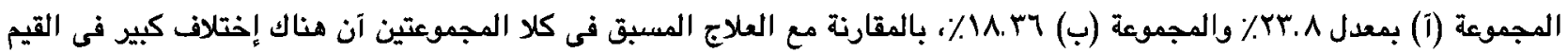

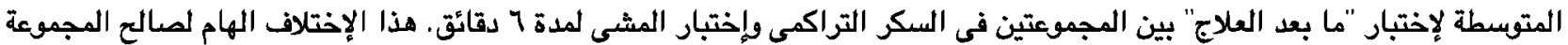 \\ آ من المجموعة ب.
}

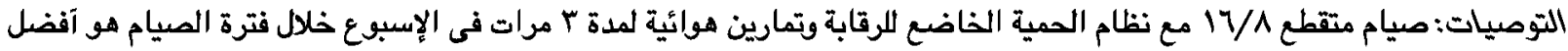

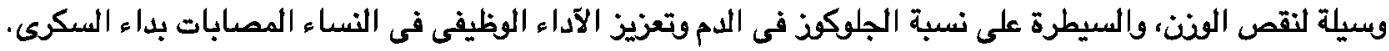

